\title{
EFFECTIVENESS OF SERIES AND PARALLEL TURBO COMPOUNDING ON TURBOCHARGED DIESEL ENGINE
}

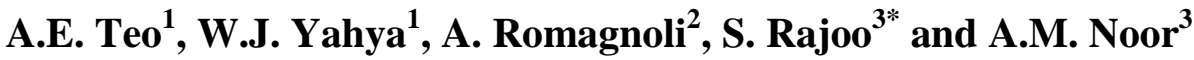 \\ ${ }^{1}$ Malaysia - Japan International Institute of Technology (MJIIT), Universiti Teknologi \\ Malaysia Kuala Lumpur, Jalan Semarak, 54100 Kuala Lumpur, Malaysia \\ ${ }^{2}$ Energy Research Institute (ERI@N) \\ Nanyang Technological University, Singapore \\ ${ }^{3}$ UTM Centre for Low Carbon Transport in cooperation with Imperial College London, \\ Universiti Teknologi Malaysia, 81310, Skudai, Johor, Malaysia \\ *Email: srithar@fkm.utm.my \\ Phone: +6075534889, Fax: +6075566159
}

\begin{abstract}
Turbo compounding is one of the ways to recover wasted energy in the exhaust. This paper presents the effectiveness of series and parallel turbo compounding on a turbocharged diesel engine. A power turbine is coupled to the exhaust manifold, either in series or in parallel with the turbocharger, to recover waste heat energy. The effectiveness and working range of both configurations are presented in this paper. The engine in the current study is a 6 cylinder, $13 \mathrm{~L}$ diesel engine. Both the configurations were modeled with one dimensional simulation software. The current study found that series and parallel turbo compounding could improve average brake specific fuel consumption (BSFC) by $1.9 \%$ and $2.5 \%$, respectively. When the power turbine is mechanically connected to the engine, it could increase the average engine power by $1.2 \%$ for the series configuration and $2.5 \%$ for the parallel configuration.
\end{abstract}

Keywords: Exhaust Energy Recovery; Waste Heat Recovery; Turbo Compound; Power Turbine.

\section{INTRODUCTION}

Increasing fuel prices and the ever stringent emissions regulations have caused manufacturers and researchers to strive to create a more efficient engine system. Various research on improving emissions and fuel economy has been undertaken [1-7]. Even so, there is still plenty of energy wasted. As high as $46 \%$ of the fuel's energy in an internal combustion engine (ICE) is lost to the surroundings in the form of exhaust heat [8-11]. This highlights the importance of recovering energy from the exhaust which is otherwise wasted. The interest and application reality of exhaust energy recovery have been amplified with its recent inclusion in Formula 1. There are various ways to extract energy from the exhaust, such as the use of the Rankine cycle, Stirling engine, and thermoelectric generators (TEG), and turbo compounding [12, 13]. This study focuses on turbo compounding as a method for exhaust energy recovery. Turbo compounding is a form of exhaust energy recovery which utilizes the power turbine to extract exhaust energy. Utilizing the Brayton cycle the power turbine can be mechanically connected to the crankshaft or connected to a generator to produce electricity. Turbo compounding dates all the way back to the time of World War 2 where it was used to improve an 
airplane's engine efficiency and performance [14]. In mechanical turbo compounding, the power turbine is linked to the crankshaft via a gear train and companies such as Volvo and Scania have implemented mechanical turbo compounding on some of their long-haul trucks [15]. Electrical turbo compounding, on the other hand, couples an electric generator to the power turbine and the electric output can be used directly or stored in a battery. Companies such as Bowman and Controlled Power Technologies (CPT) have produced an electric turbo-compounding system that can be used to extract wasted exhaust energy. Since 2014, Formula 1 cars have also utilized a form of electric turbo compounding, but instead of a secondary power turbine, a motor generator is coupled to the turbocharger. This allows it to work simultaneously as both the generator to harvest extra power from the exhaust as well as the motor to help spool the turbocharger when required. Various work has also been done to analyze the pulsating flow of the exhaust of an ICE so as to better predict the performance of the turbocharger [16-18]. The objective of this study to investigate the effectiveness of series and parallel turbo compounding on turbocharged diesel engine.

\section{METHODOLOGY}

Two turbo-compounding configurations were studied: the series and parallel configurations. For the series configuration, the power turbine was installed after the main turbocharger to extract extra exhaust energy, whereas for the parallel configuration, the power turbine was connected to two cylinders specifically dedicated to turbo compounding, with the other four used by the turbocharger. The parallel turbocompounding setup is unique as it does not require a regulating valve. Both configurations can be seen in Figure 1. For the case of parallel turbo compounding, since only four cylinders are driving the main turbocharger, it must be reconfigured to follow the reduced exhaust mass flow. The two cylinders that drive the power turbine must also be correctly paired to avoid exhaust gas pulse interference. The effect of the series and parallel configurations will then be presented so as to better understand their feasibility and working range.

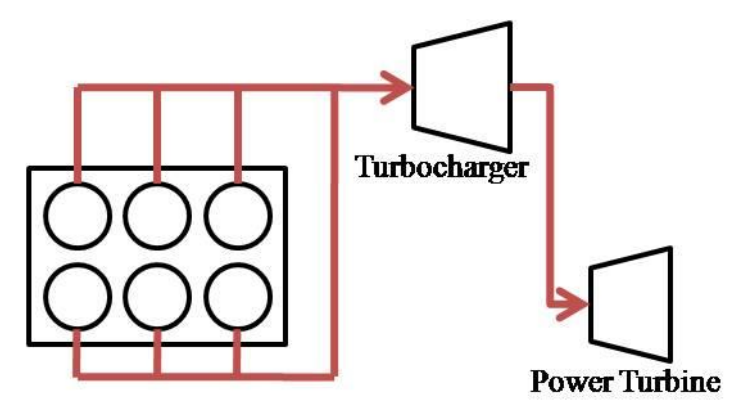

(a)

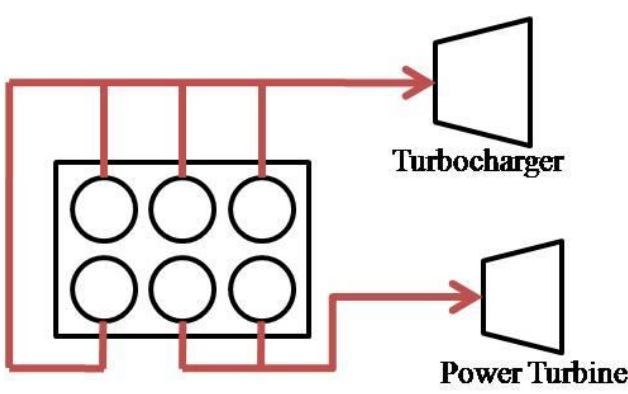

..(b)

Figure 1. Configuration of (a) series and (b) parallel turbo compounding.

\section{Governing Equations}

The governing equations consist of energy, momentum and mass conservation, solved along the mean path-line of the flow. Equations of mass and energy are solved for each volume and the momentum equation is solved for each boundary between the volumes. The equations are written in an explicitly conservative form in Eqs. (1)-. 
Equation (1): Mass continuity equation

$$
\frac{d m}{d t}=\sum_{\text {boundaries }} m_{f l u x}
$$

Equation (2): Conservation of momentum equation

$$
\frac{d\left(m_{\text {flux }}\right)}{d t}=\frac{d p A+\sum_{\text {boundaries }}\left(m_{\text {flux }} u\right)}{d x}-\frac{4 C_{f} \frac{p u^{2} d x A}{2 D}-C p\left(\frac{1}{2} p u^{2}\right) A}{d x}
$$

Equation (3): Conservation of energy equation

$$
\frac{d(m e)}{d t}=p \frac{d V}{d t}+\sum_{\text {bound }} m_{\text {flux }} H-h_{g} A\left(T_{\text {gas }}-T_{\text {wall }}\right)
$$

The engine power is governed by Eq. (4)

$$
P_{\text {engine }}=B M E P . V_{D} \cdot \eta_{\text {cycle }}
$$

where $\eta_{\text {cycle }}$ is the number of cycles per second

For turbine simulation, the performance characteristics along a line of constant turbine speed were used. The power provided by the turbine is determined by the turbine mass flow rate and the enthalpy difference across the turbine, as seen in Eqs. (5) and (6).

$$
\begin{gathered}
P_{T}=\dot{m}_{T} \cdot \eta_{m} \cdot\left(h_{3}-h_{4}\right) \\
h_{3}-h_{4}=\eta_{s, T} \cdot c_{p} \cdot T_{3} \cdot\left[1-\left(\frac{p_{4}}{p_{3}}\right)^{\frac{k-1}{k}}\right]
\end{gathered}
$$

where $\kappa$ is the ratio of specific heats

\section{Selection of Engine}

The engine used for this study is a $13 \mathrm{~L}, 6$ cylinder in-line turbocharged intercooled diesel. Table 1 shows the engine's specifications and performance characteristics [19].

Table 1. SCANIA engine specification.

\begin{tabular}{lc}
\hline \multicolumn{2}{c}{ Scania Engine, DC13-06 } \\
\hline Capacity & $12.74 \mathrm{~L}$ \\
Bore & $130 \mathrm{~mm}$ \\
Stroke & $160 \mathrm{~mm}$ \\
Compression Ratio & $17: 1$ \\
Maximum Power & $265 \mathrm{~kW} \mathrm{@} \mathrm{1900} \mathrm{RPM}$ \\
Maximum Torque & $1850 \mathrm{Nm} @ 1300 \mathrm{RPM}$ \\
\hline
\end{tabular}


The engine has installed an integrated turbo charging system and this setup was used as the benchmark in the current study. Performance of the proposed series and parallel turbo-compounding systems was compared against the original setup. Three models were produced in the current study, one replicating the original engine setup as in Table 1 and another two using the original engine coupled with a power turbine, either in series or parallel with the main turbocharger, as in Figure 1. Models were built and simulated using AVL BOOST software [20].

\section{Modeling of Original Engine}

Figure 2 shows the AVL BOOST model of the original engine system. The main purpose of modeling the original engine is to have a benchmark engine performance which can then be compared to the turbo compounded engines. All of the crucial parameters are set according to the manufacturer's specification sheet.

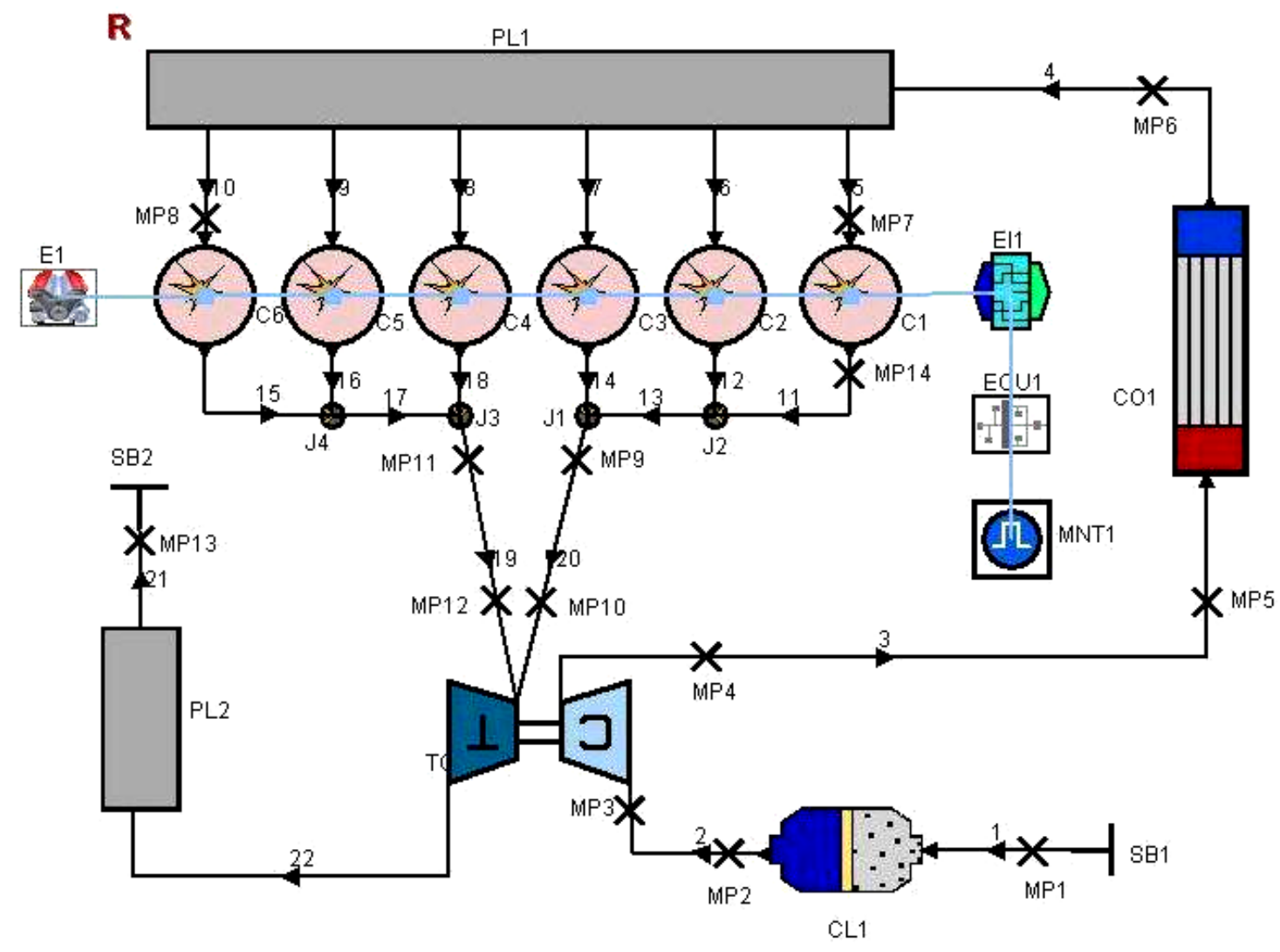

Figure 2. AVL model of the original engine.

\section{Validation of the Engine Model}

As the real engine is not available for testing, the engine model is validated with the power curve and torque curve obtained from the manufacturer's specifications sheet. Figure 3 shows the comparison of the power and torque curves between the model and the real engine specifications. At the lower range around 1000-1300 rpm, the difference between the model and the real engine is on average about $6 \%$ for the power curve and, at the higher end, the average difference is around 3\%. For the torque curve, the model 
deviates from the real engine by about $4.8 \%$ at the lower range and about $4.5 \%$ from 1300 RPM and above. Overall, the average difference between the model and the real engine is about $4 \%$.

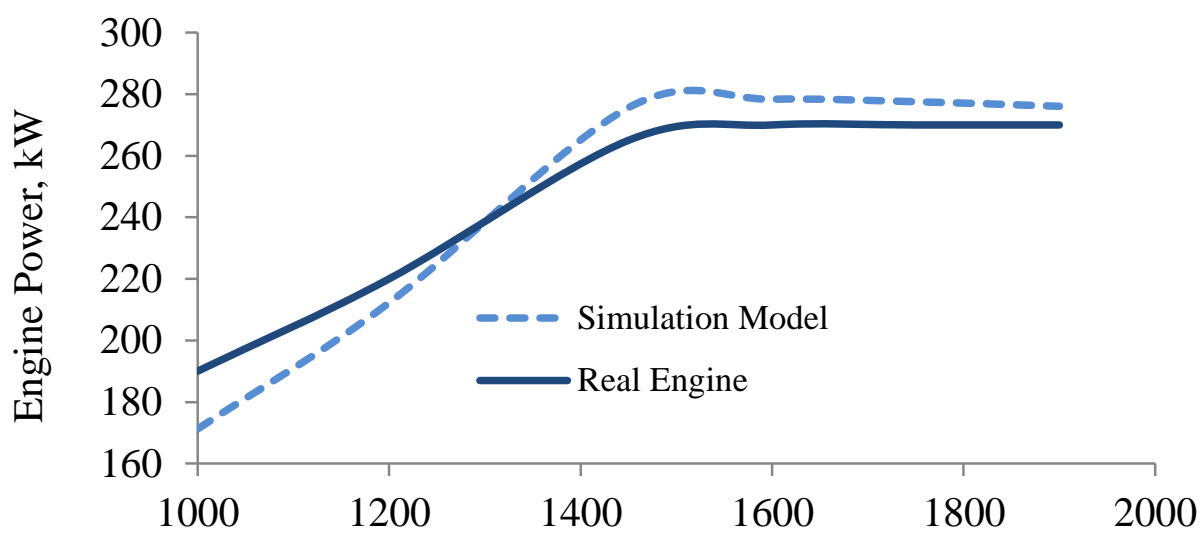

Engine Speed, RPM

(a)

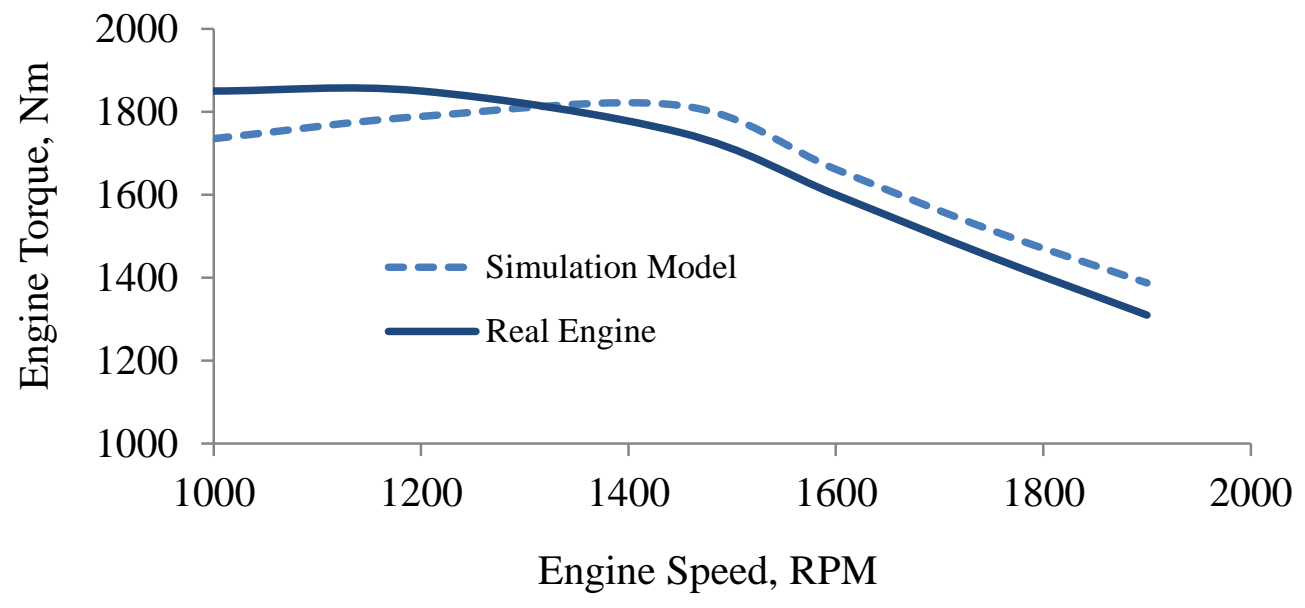

(b)

Figure 3. Comparison of the simulation model and real engine (a) power and (b) torque curves.

\section{Selection of Power Turbine}

The power turbine is the most important component in turbo compounding as it is responsible for converting exhaust gas energy to useful work. For the series configuration, the pressure available downstream is relatively low and there is very limited choice of commercially available turbines that can efficiently work in that condition. Thus, to fully take advantage of this condition, a low pressure turbine must [21] be carefully designed as in reference However, for this initial study, a standard turbocharger turbine is used as the power turbine. The chosen model is a Garrett GT4508R turbine, with housing size of 85 Trim, and area-to-radius ratio of 1.44 for the series configuration and a Garrett GT2860R turbine, with housing size of 76 Trim, and 
area-to-radius ratio of 0.64 for the parallel configuration [22]. Figure 4 shows the engine operating points plotted on the turbine maps.

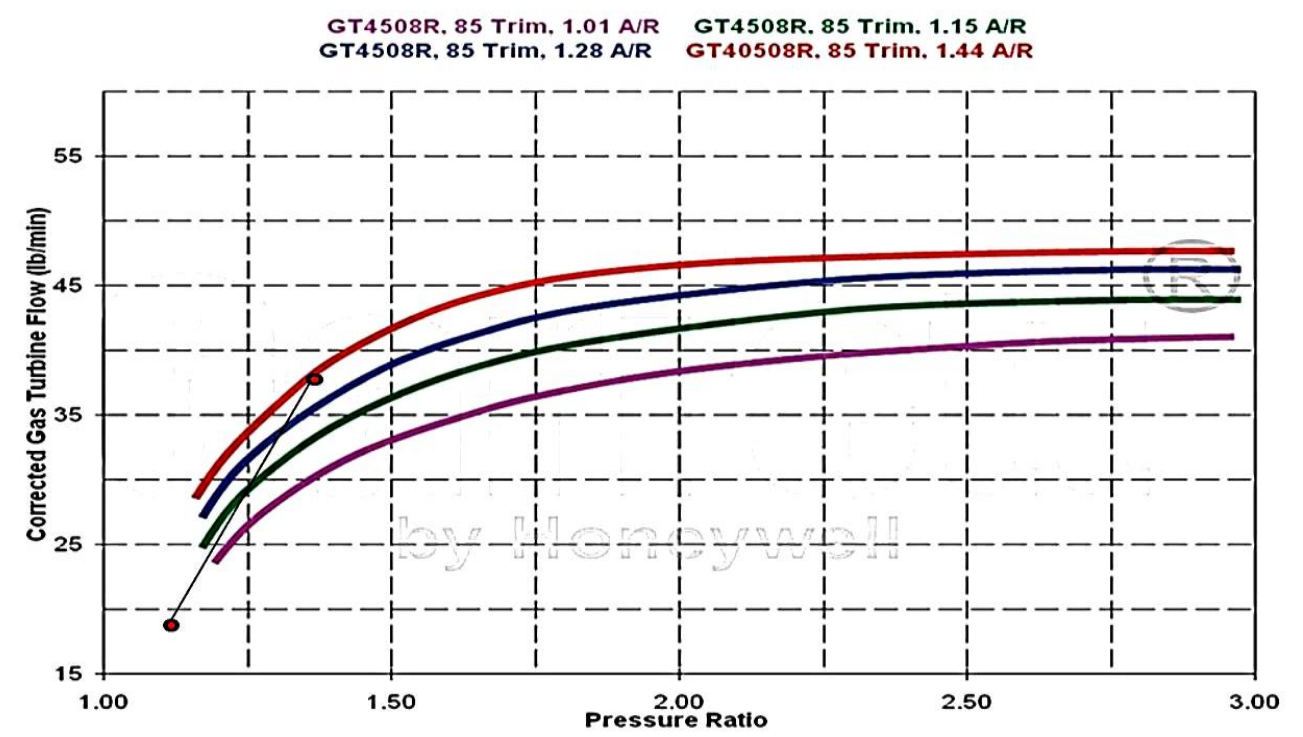

(a)

GT2860R. 76 Trim. 0.64 A/R

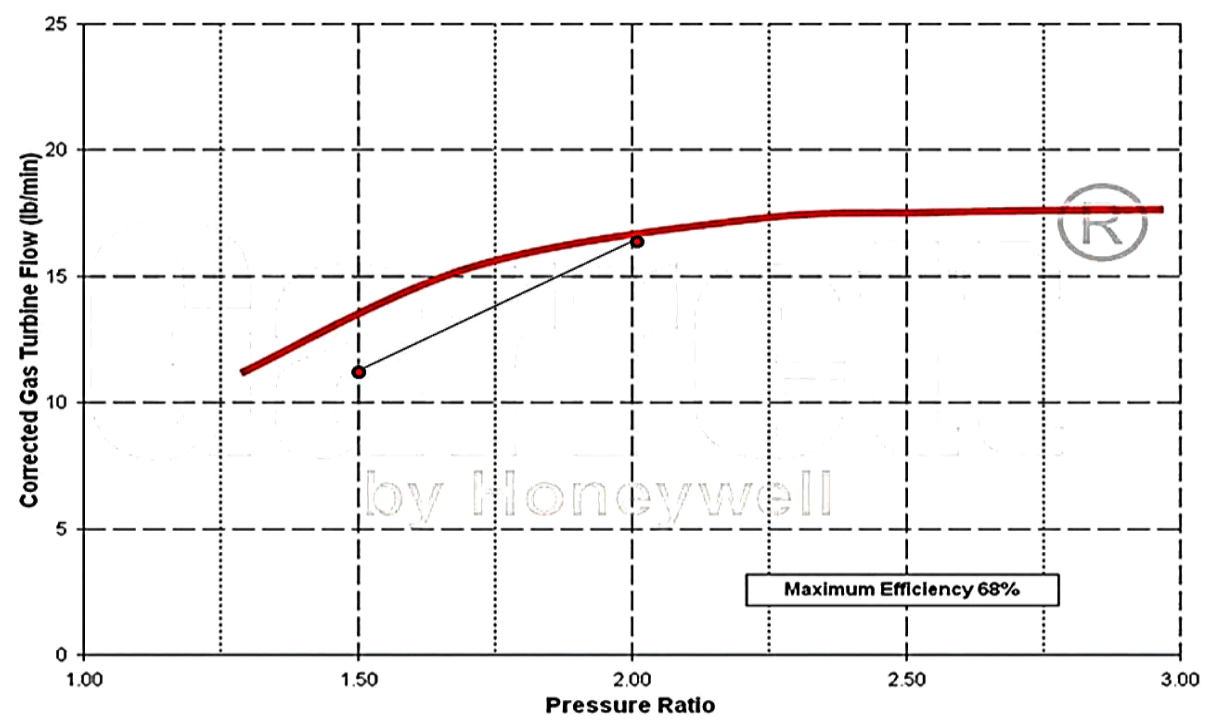

(b)

Figure 4. Engine operating points plotted on turbine maps for (a) series and (b) parallel systems [22].

\section{Modeling of Turbo Compounded Engine}

Figure 5 shows the model for both series and parallel turbo-compounding configurations. The main difference from the original engine is the inclusion of the power turbine in the model. For both the configurations, the power turbine is 
mechanically connected to the engine to provide additional power. The efficiency of the mechanical connection is set at $97 \%$.

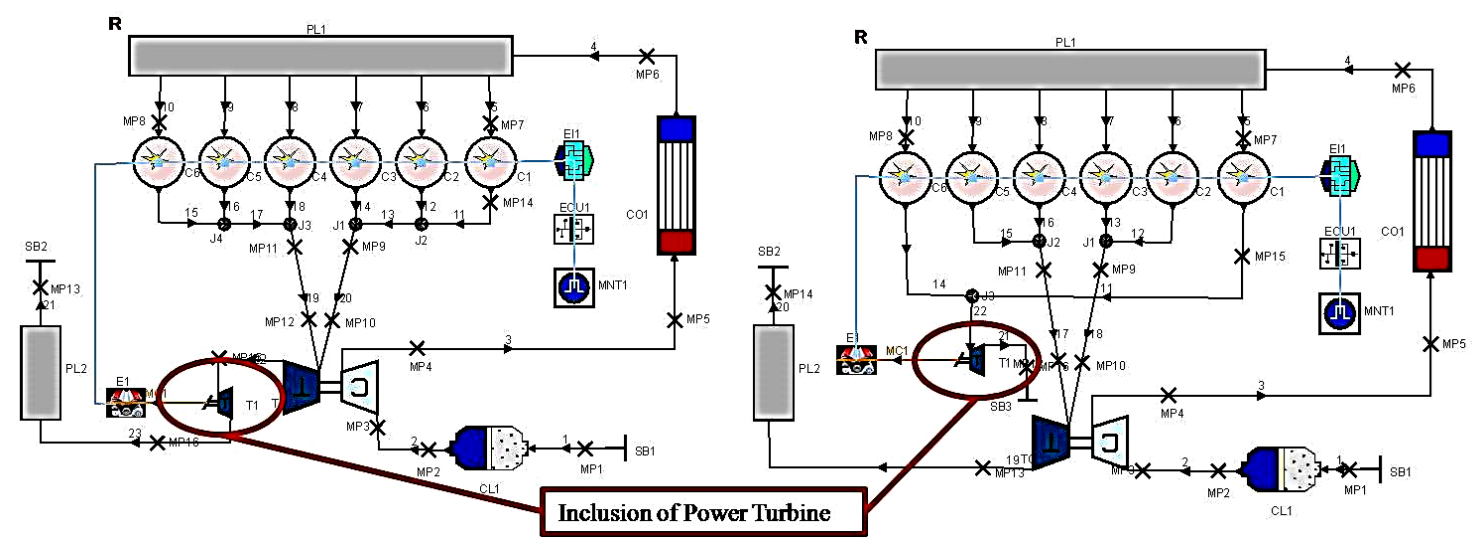

Figure 5. AVL model of series (left) and parallel [23] turbo compounding.

\section{RESULTS AND DISCUSSION}

The effectiveness of both series and parallel turbo compounding is presented in this section. For the case of series turbo compounding, the engine power will deteriorate as the inclusion of the power turbine downstream will produce back pressure. However, when the power turbine can produce and extract adequate power from the exhaust to more than compensate for the drop, a total improvement can be obtained. As for the case of parallel configuration, back pressure would not be much of an issue. Back pressure actually has its own merit in that it facilitates internal exhaust gas recirculation (EGR) but the emission effect is not considered in this study and thus viewed negatively, as it causes engine performance to drop. Power extracted by the power turbine will be transferred directly to the engine's crankshaft via a mechanical connection to improve engine power. The engine's performance for both turbocompounding configurations is shown in Figure 6.

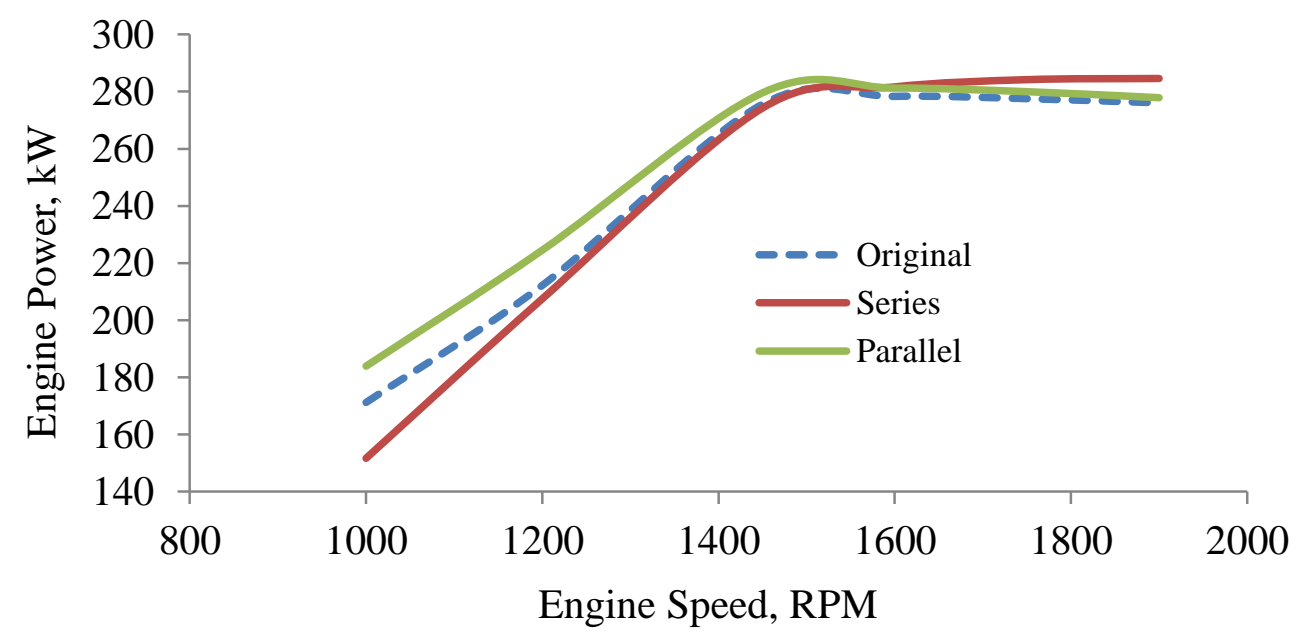

Figure 6. Comparison of total engine power for original and turbo compounded engines. 
Figure 6 shows that for the series configuration, the engine power is actually lower compared to the original and parallel configurations at 1000-1400 RPM. At low engine speed, the engine power is actually reduced by an average of $6.3 \%$ compared to the original engine. One of the main reasons for this is the unwanted back pressure imposed by the power turbine [13]. However, at higher engine speeds, the effect of back pressure is much lower as power actually improves by as much as $3.1 \%$ compared to the original engine for speeds above 1400 RPM. Taking into consideration the whole engine range, the improvement is almost negligible. This highlights the importance of a by-pass system that can by-pass the power turbine at low engine speeds and hence eliminate unwanted back pressure. The power turbine will then only be used when an improvement can be obtained, especially at mid to high engine speeds. When a by-pass system is incorporated, an average improvement of $1.2 \%$ can be gained. For the parallel configuration, it can be seen that the power is actually higher than the original engine at all engine speeds. The average improvement across the range is $2.5 \%$. This is because back pressure is no longer an issue. Even so, there is less improvement at the higher range compared to the series configuration. One of the reasons for this is that there is less available energy to extract in the parallel configuration as the mass flow of the exhaust is reduced. Since only two cylinders are used to drive the power turbine, the maximum available energy is lower compared to the series configuration. This can be seen in Figure 7.

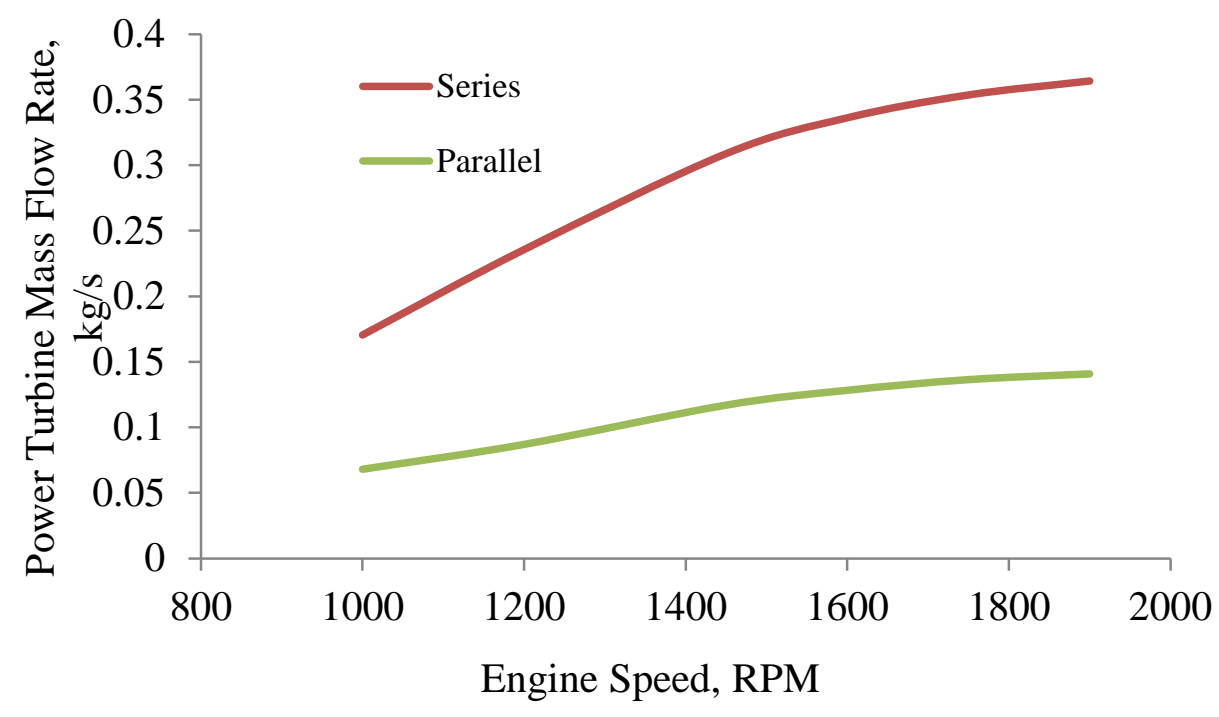

Figure 7. Exhaust mass flow entering the power turbine for both configurations.

The power turbine is responsible for converting waste exhaust energy to useful work. Figure 8 shows the pressure ratio of the power turbine for both configurations. The pressure ratio across the series power turbine is much lower compared to the parallel power turbine. This is because the pressure available downstream of the turbocharger is very low [21]. However, this does not necessarily mean that the parallel power turbine produces the most power. The power extracted by both power turbines can be seen in Figure 9. 


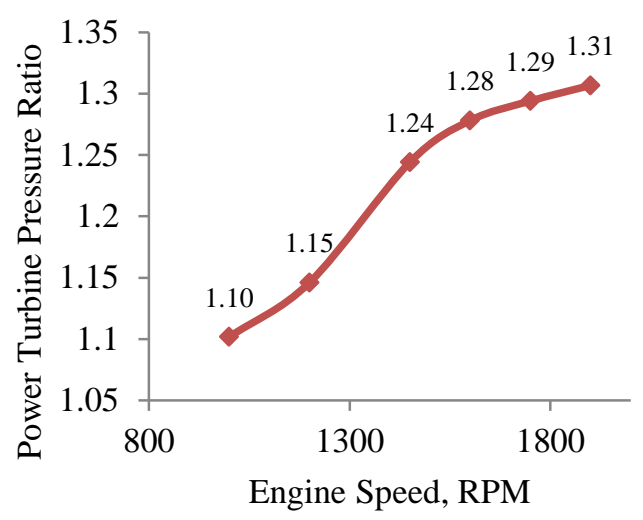

(a)

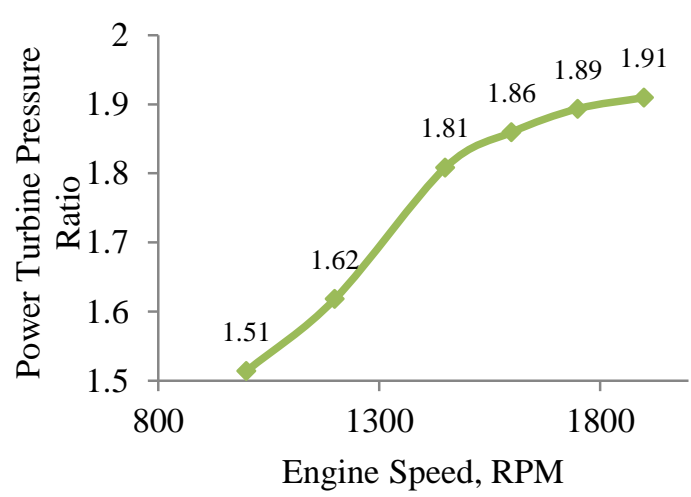

(b)

Figure 8. Power turbine pressure ratio for (a) series and (b) parallel configurations.

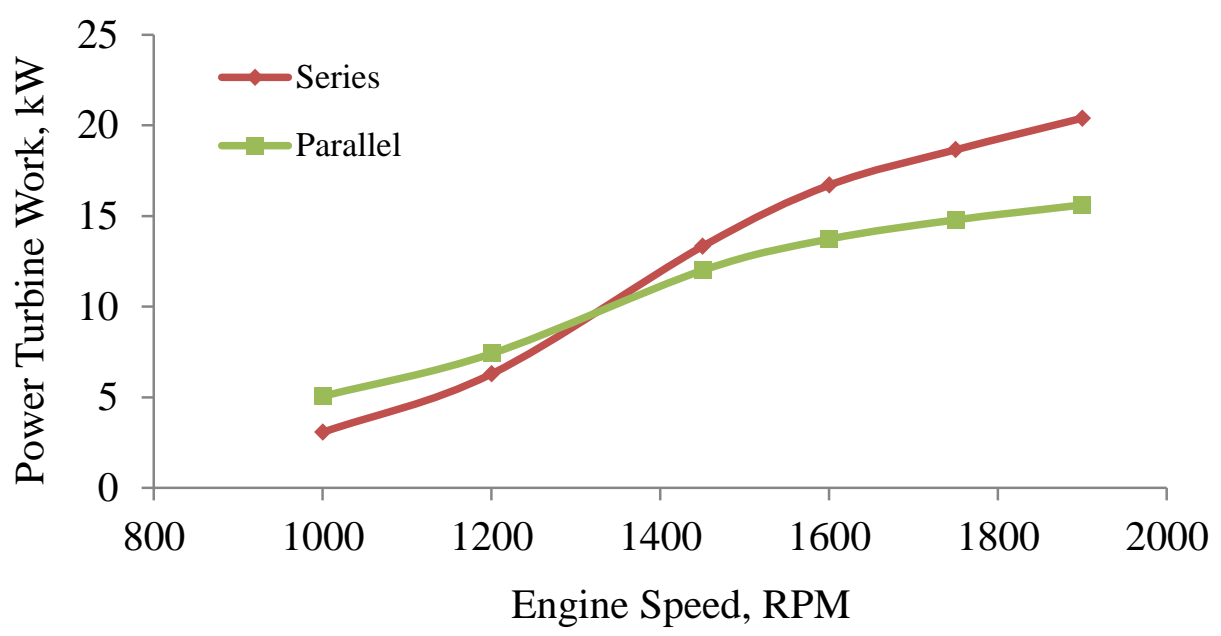

Figure 9. Power turbine work for turbo compounded engines.

In Figure 9, the series power turbine can extract more energy from the exhaust at mid to high engine speeds. Although it works at a lower pressure ratio, the mass flow is higher hence the capability of extracting more from the exhaust. Another aspect of turbo compounding that is of interest is the potential for fuel saving. Figure 10 shows the comparison of brake specific fuel consumption (BSFC) of the original engine and the turbo compounded ones. In Figure 10, the series turbo compounding shows an increase in BSFC and only shows improvements at higher engine speeds. This again is due to the existence of back pressure. At lower engine speeds, the BSFC increases by as much as $12.8 \%$ compared to the original engine. At higher engine speeds, the BSFC can be reduced by $3 \%$ at most. Considering the whole engine range, the BSFC actually increases by about $1.7 \%$ and this again highlights the importance of a by-pass system. With a by-pass system installed, the average BSFC reduction is about $1.9 \%$. In the case of the parallel configuration, the BSFC is actually reduced over the whole engine operating range and gives an average BSFC improvement of $2.5 \%$. The maximum BSFC reduction is about $7 \%$. Nevertheless, at high engine speeds, the series configuration achieves better BSFC improvement. This is due to the reduced exhaust mass flow mentioned earlier. It is shown that series turbo compounding can only show 
improvement at mid to high engine speeds and suffers tremendously at low engine speeds. Back pressure is the main culprit. Parallel turbo compounding on the other hand shows improvement at all engine speeds and achieves better overall improvement in terms of engine power and BSFC compared to its series counterpart. This does not necessarily mean that parallel turbo compounding is better than series. It all depends on the application and intended use. Series turbo compounding might prove beneficial on a system that constantly works at higher engine speeds as it provides more improvement compared to parallel turbo compounding. On the other hand, parallel turbo compounding might prove more beneficial where the engine works at variable speeds, such as in an automobile in urban areas, where it is frequently driven in a start-stop manner.

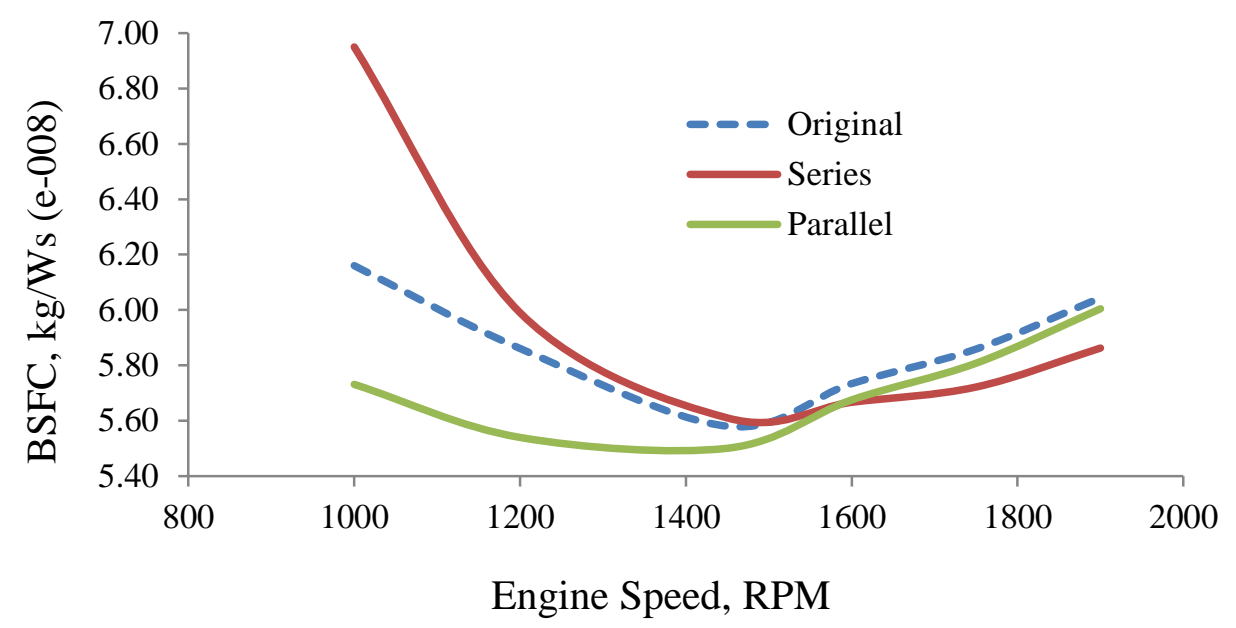

Figure 10. Comparison of engine BSFC for original and turbo compounded engines.

\section{CONCLUSIONS}

Both series and parallel turbo compounding were simulated with one dimensional simulation software and their effectiveness was presented. Series turbo compounding can provide an average improvement in engine power by $1.2 \%$ and BSFC by $1.9 \%$ when a by-pass valve is used. At low engine speed, its performance suffers due to back pressure. Parallel turbo compounding on the other hand can give an average improvement of $2.5 \%$ for both engine power and BSFC across the whole engine range. Applications where the engine speed varies, such as in an automobile, might favor parallel turbo compounding. As the real engine is not available for testing and experimentation, there is still much room for improvement regarding the engine model. Nonetheless, this study serves to give a preliminary view of the effectiveness of series and parallel turbo compounding.

\section{ACKNOWLEDGEMENTS}

The authors would to thank The Ministry of Higher Education Malaysia and Universiti Teknologi Malaysia for Flagship Grant Vot 01G49. 


\section{REFERENCES}

[1] Abdullah NR, Shahruddin NS, Mamat R, Ihsan Mamat A, Zulkifli A. Effects of air intake pressure on the engine performance, fuel economy and exhaust emissions of a small gasoline engine. Journal of Mechanical Engineering and Sciences. 2014;6:949-58.

[2] Yusop A, Mamat R, Mat Yasin M, Ali OM. Effects of particulate matter emissions of diesel engine using diesel-methanol blends. Journal of Mechanical Engineering and Sciences. 2014;6:959-67.

[3] Hairuddin AA, Wandel AP, Yusaf T. An introduction to a homogeneous charge compression ignition engine. Journal of Mechanical Engineering and Sciences. 2014;7:1042-52.

[4] Kapilan N, Ashok Babu TP, Reddy RP. Improvement of performance of dual fuel engine operated at part load. International Journal of Automotive and Mechanical Engineering. 2010;2:200-10.

[5] Azad AK, Ameer Uddin SM, Alam MM. A comprehensive study of DI diesel engine performance with vegetable oil: an alternative boi-fuel source of energy. International Journal of Automotive and Mechanical Engineering. 2012;5:57686.

[6] Soon LB, M. Rus AZ, Hasan S. Continuous biodiesel production using ultrasound clamp on tubular reactor. International Journal of Automotive and Mechanical Engineering. 2013;8:1396-405.

[7] Yusaf T, Hamawand I, Baker P, Najafi G. The effect of methanol-diesel blended ratio on CI engine performance. International Journal of Automotive and Mechanical Engineering. 2013;8:1385-95.

[8] Stobart R, Weerasinghe R. Heat recovery and bottoming cycles for SI and CI engines-a perspective. SAE Technical Paper No. 2006-01-0662; 2006.

[9] Mat Yasin MH, Mamat R, Sharma KV, Yusop AF. Influence of palm methyl ester (PME) as an alternative fuel in multicylinder diesel engine. Journal of Mechanical Engineering and Sciences. 2012;3:331-9.

[10] Rahim R, Mamat R, Taib MY, Abdullah AA. Influence of fuel temperature on a diesel engine performance operating with biodiesel blended. Journal of Mechanical Engineering and Sciences. 2012;2:226-36.

[11] Ghobadian B, Najafi G, Nayebi M. A semi-empirical model to predict diesel engine combustion parameters. Journal of Mechanical Engineering and Sciences. 2013;4:373-82.

[12] Hountalas D, Katsanos C, Lamaris V. Recovering energy from the diesel engine exhaust using mechanical and electrical turbocompounding. SAE Technical Paper No. 2007-01-1563; 2007.

[13] Jye AETS, Pesiridis A, Rajoo S. Effects of mechanical turbo compounding on a turbocharged diesel engine. SAE Technical Paper No. 2013-01-0103; 2013.

[14] Vuk CT. Electric turbo-compounding: a technology whose time has come. Technical Session2005.

[15] Greszler A. Diesel turbo-compound technology. Proceedings of DEER Confrerence, Dearborn, MI, USA. 2008;47.

[16] Chiong MS, Rajoo S, Martinez-Botas RF, Costall AW. Engine turbocharger performance prediction: One-dimensional modeling of a twin entry turbine. Energy Conversion and Management. 2012;57:68-78. 
[17] Chiong MS, Rajoo S, Romagnoli A, Costall AW, Martinez-Botas RF. Integration of meanline and one-dimensional methods for prediction of pulsating performance of a turbocharger turbine. Energy Conversion and Management. 2014;81:270-81.

[18] Chiong MS, Rajoo S, Romagnoli A, Costall AW, Martinez-Botas RF. Nonadiabatic pressure loss boundary condition for modelling turbocharger turbine pulsating flow. Energy Conversion and Management. 2015;93:267-81.

[19] Limited SGB. Truck specification sheets - Euro 5. SCANIA (Great Britain) Limited2015.

[20] GmbH AL. Home - avl.com. AVL LIST GmbH.

[21] Mamat AM, Padzillah MH, Romagnoli A, Martinez-Botas RF. A high performance low pressure ratio turbine for engine electric turbocompounding. ASME 2011 turbo expo: turbine technical conference and exposition: American Society of Mechanical Engineers. 2011: 771-84.

[22] Honeywell Gb. Products | Turbochargers.: Garrett by Honeywell.

[23] Trent EM, Wright PK. Metal cutting. 4th ed. Boston, USA: Butterworth/Heinemann; 2000. 